\title{
Population aging and the historical development of intergenerational transfer systems
}

\author{
Ronald Lee(1)
}

\author{
Correspondence: rlee@demog. \\ berkeley.edu \\ Departments of Demography and \\ Economics, University of California, \\ Berkeley, 2232 Piedmont Ave, \\ Berkeley, CA 94720, USA
}

\begin{abstract}
From our evolutionary past, humans inherited a long period of child dependency, extensive intergenerational transfers to children, cooperative breeding, and social sharing of food. Older people continued to transfer a surplus to the young. After the agricultural revolution, population densities grew making land and residences valuable assets controlled by older people, leading to their reduced labor supply which made them net consumers. In some East Asian societies today, elders are supported by adult children but in most societies the elderly continue to make private net transfers to their children out of asset income or public pensions. Growing public intergenerational transfers have crowded out private transfers. In some high-income countries, the direction of intergenerational flows has reversed from downward to upwards, from young to old. Nonetheless, net private transfers remain strongly downward, from older to younger, everywhere in the world. For many but not all countries, projected population aging will bring fiscal instability unless there are major program reforms. However, in many countries population aging will reduce the net cost to adults of private transfers to children, partially offsetting the increased net costs to working age adults for public transfers to the elderly.

Keywords: Population aging, Intergenerational transfer, Demographic transition, Old age, Support system, Sharing, Welfare state
\end{abstract}

\section{Introduction}

An intergenerational transfer is a transfer of money or goods by one person to another of a different age or generation, with no quid pro quo and no expectation of repayment. Private intergenerational transfers include the parental costs of rearing a child or supporting an elderly relative or helping an adult child with the costs of a grandchild or a mortgage. End of life bequests are also important but will not be discussed here. Public intergenerational transfers include paying taxes to fund public pensions, health care, or education. Intergenerational transfers are quantitatively important, amounting to $55 \%$ of GDP on average in a collection of rich and developing countries (Lee \& Donehower, 2011). Here I will discuss the evolutionary origins of intergenerational

(c) The Author(s). 2020 Open Access This article is licensed under a Creative Commons Attribution 4.0 International License, which permits use, sharing, adaptation, distribution and reproduction in any medium or format, as long as you give appropriate credit to the original author(s) and the source, provide a link to the Creative Commons licence, and indicate if changes were made. The images or other third party material in this article are included in the article's Creative Commons licence, unless indicated otherwise in a credit line to the material. If material is not included in the article's Creative Commons licence and your intended use is not permitted by statutory regulation or exceeds the permitted use, you will need to obtain permission directly from the copyright holder. To view a copy of this licence, visit http://creativecommons.org/licenses/by/4.0/. 
transfer behavior, describe intergenerational transfers for countries at different levels of economic development in different parts of the world, and consider how population aging will interact with intergenerational transfer systems in the coming decades. The paper makes sweeping generalizations that are often speculative, but also brings empirical evidence from quantitative studies in many social contexts.

I take a very long view of systems of intergenerational transfers. The human life cycle, as observed today, has an extended period of economic dependency in childhood and another in old age, sustained by intergenerational transfers from the surplus produced at intermediate ages. One might think that old age dependency is rooted in biology while protracted child dependency is created by the need of modern economies for well-educated workers. This view is only partially correct, and it will be useful to take a brief excursion through the evolutionary background on work, dependency, and intergenerational transfers.

\section{The evolutionary background for intergenerational transfers}

The strong sociality of human hunter gatherers is expressed in support of children up to age 20 through intergenerational transfers, and by food sharing among kin and nonkin. The roots of such behavior are deep in our past and in more recent times find expression in a variety of culturally moderated practices to be explored later.

First, consider the evolutionary background for human altruism and sociality. Among primates, human offspring grow exceptionally slowly and have a very long period of dependence. While various explanations have been advanced, there is evidence that slow growth reflects the heavy energetic requirements of the growing brain, which at birth requires more than $50 \%$ of resting metabolic energy (RME) and in childhood requires about two thirds of RME. The energetic demands of the brain are inversely correlated with the rate of weight gain of the developing child (Kuzawa et al., 2014). The brain is at the center of the human evolutionary strategy, and the investments it requires lead to a period of nutritional dependence that extends up to age 18 or 20 according to anthropological studies of hunter-gatherer groups over the past half century (Howell, 2010; Kaplan, 1994; Lee, 2000).

Because children were dependent for so long, their mothers typically had multiple simultaneously dependent children to care for and provision, setting them apart from other primates which wait until an offspring can forage for itself before reproducing again. It would not have been possible for human mothers to manage without very substantial assistance from other family members and even unrelated helpers (Hrdy, 2009). This is a form of cooperative breeding (Hill \& Hurtado, 2009; Sear \& Mace, 2008) featuring allomaternal care provided by the father and grandparents of the children, but also by cousins, aunts, uncles, and non-kin. A study by Burkart et al. (2014) found such cooperative breeding or allomaternal care to be the best predictor of prosocial "hypercooperative" (altruistic) behavior across species.

The long period of development required by the human brain is made possible by intergenerational transfers from many adults. The participation of non-kin is made possible by human altruism and sociality. An adult in one generation feeds and cares for her child in the next generation. The child never repays the adult. Instead, the child herself grows up to become an adult and a mother and feeds and cares for her own children in the subsequent generation, and so on. Social sharing is another evolved 


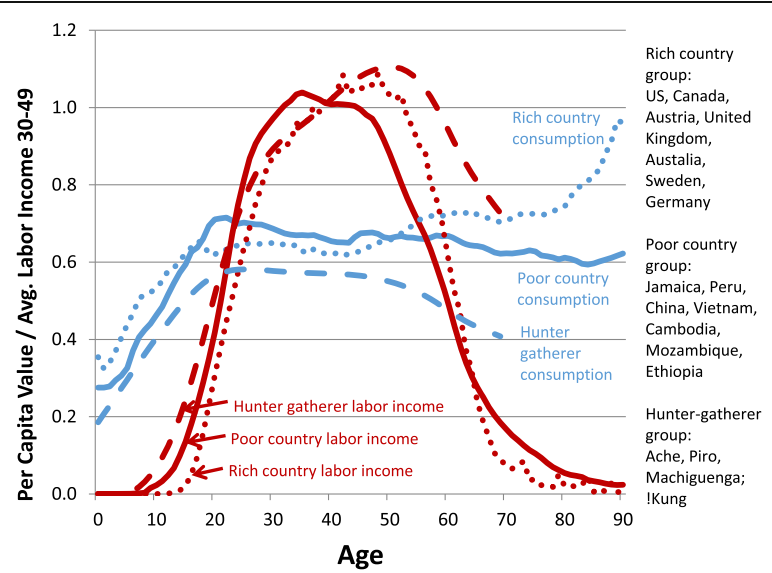

Fig. 1 Age profiles of HG, lower income, high income. Source: Calculated from National Transfer Accounts age profiles of consumption and labor income that are publicly available at the website ntaccounts.org. Lines are unweighted averages of data for the countries listed. Hunter-gatherer line is a weighted average of data from Kaplan (1994, all groups but !Kung) and Howell (2010, !Kung). !Kung is weighted one half, and each of the other three groups is weighted one sixth. See text

behavior related partly to the need for help beyond the family (Hrdy, 2009) and partly to the high variance of returns to big game hunting which required risk pooling for survival, with hunters in many groups successful on only 3 to $25 \%$ of their outings (Hill \& Hurtado, 2009). In hunter-gatherer groups, there can be asymmetry in sharing, where a family with more dependent children and a higher dependency ratio is systematically helped (Gurven, 2004; Kaplan \& Gurven, 2005).

These points are illustrated by the age profiles of consumption and labor income for hunter-gatherers shown in Fig. 1, which also shows other profiles to be discussed later. For hunter-gatherers, labor income is measured as the caloric value of food brought into camp, and consumption is calculated based on the calories available in each sharing group (typically several households), allocated to individuals in proportion to their caloric needs (Howell, 2010; Kaplan, 1994; Lee, 2000). All the age profiles shown in the figure have been standardized by dividing by the average labor income at ages 30-49 to make their shapes visually comparable. The profiles in Fig. 1 are the average of data for the !Kung in Botswana (Howell, 2010) and the average of the Ache, Piro, and Machiguenga, all groups in the Amazon Basin. ${ }^{1}$

There are two striking features of the age profiles. First, the youth do not become nutritionally self-sufficient until around age 20 , consistent with the earlier discussion. Calculations show that the net cost to achieve one child that survives to maturity is 10 or 12 years of average adult consumption (Lee, Kaplan, \& Kramer, 2002). Second, the elderly are still net producers at age 70, the last age observed in the data. From this, we see that parental and grandparental provisioning of children is not repaid. On average, adults produced more calories than they consumed at all ages observed and transferred

\footnotetext{
${ }^{1}$ That is, the weights in the average are one half for the !Kung and one sixth for each of the three Amazon Basin groups.
} 
the surplus to children. There was no retirement, and no extended period in which a child could have repaid them.

\section{Why did parental investments in offspring evolve?}

In a sense, all reproduction is an intergenerational transfer, since it involves the transfer of some resources in the form of an egg or a seed or a new body, a transfer that will never be repaid to the parent. But in the case of some species, this process of parental investment in offspring continues following birth, perhaps for months or years. Why would such apparently altruistic behavior have evolved?

Consider the young offspring of some species acquiring food energy and then allocating it among growth, survival, and reproduction. An additional calorie of energy would have some marginal impact on the offspring's lifetime reproductive fitness. An additional calorie would also have a marginal impact on the fitness of the mother of this offspring. If the marginal fitness gain from the mother's consumption of the calorie is less than one half the marginal fitness gain for her offspring (one half, because the mother shares only half her genes with her offspring), then the mother could raise her reproductive fitness by transferring the calorie to her offspring rather than consuming it herself. ${ }^{2}$ In this way, natural selection could lead to the evolution of intergenerational transfers to offspring in some species, but in other species, the criterion might not be met (for a detailed discussion see Lee, 2014; Chu \& Lee, 2006, 2012, 2013). In the case of human offspring, their hungry brains evidently yielded a high fitness rate of return on transfers of food to children.

This argument can account for downward transfers from adults to offspring, but what of the reverse, from adult children to the elderly? Chu and Lee (2013) show that in theory this could evolve as part of an efficient division of labor between grandmother and mother to invest in food and care time for the offspring. In general, however, the evolutionary perspective strongly suggests that if intergenerational transfers do occur, they should flow downwards from older to younger ages.

\section{Intergenerational transfers in agricultural settings}

With the Neolithic revolution came agricultural practices appropriate to land-abundant settings, such as forest fallow and bush fallow (Boserup, 1965, 1981). At these low population densities, land has little economic value at the margin and individual property rights are not defined, with communal control of usage.

Empirical evidence is scarce, but Kramer (2005) and Lee and Kramer (2002) present estimates of production and consumption by age for an isolated Mayan village in Yucatan practicing forest fallow agriculture. The profiles for both males and females indicate that adults continue to produce more than they consume through the end of observation which, in this study, is in their early 60s. All adults contribute to providing food for the many children in the population. The children themselves produce more than in the hunter-gatherer populations, but adult surplus net production is less.

Children in this setting become productive earlier than hunter-gatherers because many productive tasks are simple and safe enough for them to perform, so the net cost

${ }^{2}$ In the case of the father, the additional gain for the child would have to be sufficiently large to overcome the uncertainty about paternity. 
of raising children to maturity is greatly reduced, as are intergenerational transfers to them. Gains from food sharing are also reduced because randomness in production across households is highly correlated, depending more on weather than on the luck of the hunt, so risk pooling is ineffective.

As populations grow and become denser and production becomes more labor intensive, the value of land rises and property rights in land begin to emerge (Boserup, 1965; Domar, 1970). As they do, people tend to accumulate property across the life cycle through saving and inheritance, and older people own assets such as land, structures, and livestock. This means that on the one hand their adult children can be productively employed on the land and on the other hand, the adult children may hope to inherit the assets when their parents die. Ownership of assets gives the elderly new options. The assets they own are productive and account for about a third of self-employment output (mixed income) with two thirds accruing to labor (Gollin, 2002).

In some settings, older adults may withdraw from labor, at least as it is measured in surveys, and they then consume more than their labor produces (Mueller, 1976; Stecklov, 1997) in contrast to older hunter-gatherers and low density agriculturalists. In other settings, the elderly may continue to work hard into old age. In the Natural Transfer Account (NTA) data to be discussed below, both cases are observed. Taking asset income into account, the elderly may be responsible for more production than they consume and may in fact make net intergenerational transfers to younger family members, even if they work little.

In some countries with large agricultural sectors, net consumption by the elderly is funded by their adult children, typically through co-residence, but among countries in the National Transfer Accounts project this is rare as I shall discuss later. More commonly, the elderly make net transfers to younger family members funded in part by their asset income and sometimes by public sector pensions.

\section{Rise of the welfare state.}

With industrialization came assets beyond agricultural and residential property, in the form of financial assets and nonagricultural capital. Saving and investment outside of family enterprise became an alternative means of providing for consumption in old age. But an equally profound change was the rise of government programs which make intergenerational transfers to children and the elderly. These public transfers involve vertical (intergenerational) redistribution of income as distinct from horizontal (intragenerational) redistribution from rich to poor without an age-specific intent. Much has been written about the growth of these new public intergenerational transfer programs, but for present purposes the theory of Becker and Murphy (1988) is particularly interesting. According to this theory, public education arises because the family, lacking an enforcement mechanism for repayment of parental loans to children, tends to underinvest in human capital. But taxing adults to pay for children's public education leaves the parental generation worse off than before (they could have spent more on their children's education had they chosen to). To fix this problem, the state later introduces a public pension program, taxing the newly educated children to compel them to reimburse their parents who were themselves compelled to pay taxes to fund public education without receiving any themselves. 


\section{Empirics of the economic life cycle}

The National Transfer Accounts project or NTA provides estimates of many of the quantities discussed earlier in this paper (for information on the project, see www.ntaccounts.org, Lee \& Mason, 2011b, and United Nations Population Division, 2013). Estimates are based on existing surveys, censuses, and administrative data, which are used to construct average values by age for variables such as labor income, consumption, and private and public intergenerational transfers. Labor income includes self-employment income, salaries and wages, and employerprovided benefits, before taxes, and averaged over the whole population including those with no labor income at all. Consumption includes household consumption expenditures allocated by age, plus public in-kind benefits received such as public education, public health care, and public assistance. Cash public transfers such as pensions are not included. All survey estimates are adjusted up or down proportionately so that, when multiplied by the population age distribution and summed, they produce totals that equal those provided in standard National Income and Product Accounts.

Figure 1 shows the most basic components of the economic life cycle-consumption and labor income by age. Consumption is private consumption expenditure (household expenditure imputed to individuals) plus in-kind government transfers (such as publicly provided health care, long-term care, and education, but not cash transfers such as pensions). Labor income is wages and salaries plus fringe benefits, plus two thirds of income from self-employment and unpaid family labor.

The age profiles for developing countries are averages for selected countries in Africa, Latin America, and Asia, as indicated on the figure, and those for rich countries are averages for Europe, N. America, and Oceania. There is considerable heterogeneity within each of these groups, but I will focus on the similarities. While older people in huntergather societies continue to be net producers at least through age 70 , we see that in developing countries they become net consumers after age 57 where the labor income and consumption lines cross. These profiles reflect a mix of agricultural and nonagricultural labor, but Stecklov (1997) using similar methods and looking separately at the rural population of Cote d'Ivoire finds an even earlier point at which older people become net consumers. In rich countries, this occurs at age 60 on average. Children in hunter-gatherer groups begin early to earn labor income, in developing countries are intermediate, and in rich countries start the latest. The peak labor income occurs latest in rich countries, but then it drops very rapidly as people become eligible for public pensions.

There are also important differences in consumption. In developing and rich countries, income is derived from assets as well as labor income which is an important reason why the consumption curves are higher in those countries. At younger ages, the rich countries show a consumption bulge reflecting human capital investment in children, indicated in the figure by the dip in consumption after age 18. Most striking is the rise in consumption across adult ages in the rich countries while it is flat or slightly declining in the developing countries and hunter-gatherer groups.

The growth of the welfare state has a profound effect on the shape of the economic life cycle. Whatever its original rationale, it has come to shape the economic rhythms of our lives. This can be seen in the changing age profiles of consumption in the USA shown in Fig. 2. In 1960, total consumption dips after age 60. In 1981, it is flat or somewhat rising across the adult ages, and by 2011, it rises strongly with age. Closer 

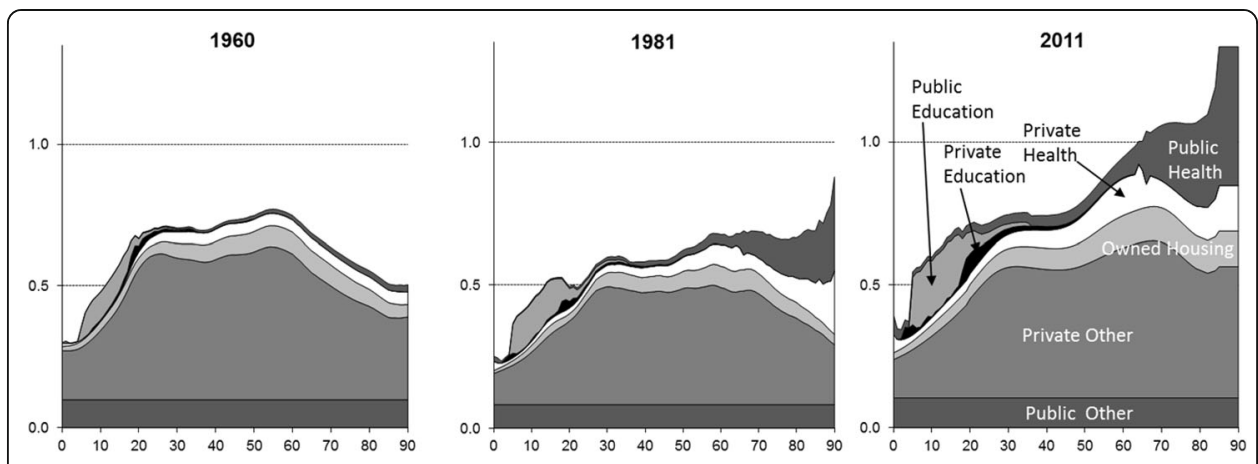

Fig. 2 Changes in age profile of US consumption over a half century. Source: Updated from Lee, Donehower and Miller (2011) using National Transfer Accounts estimates

inspection reveals that the tilt toward higher old age consumption is largely due to increased public provision of health care to the elderly, mainly through Medicare and Medicaid, two programs begun in the mid-1960s. It is also likely that increased coverage and generosity of Social Security pension benefits have been at least partly responsible for the increasing age gradient in private consumption expenditure. By 2011, the ratio of consumption at age 80 to age 20 had more than doubled relative to 1960. Similar changes have been documented in Sweden and (over a shorter time span) in Japan.

Combined with substantial declines in retirement age during the twentieth century in Europe and its offshoots, these changes in the economic life cycle have greatly increased the relative social cost of old age. Simply put, the elderly now consume more and work less, making population aging even more costly. Since the mid-1990s, however, there has been a modest reversal in OECD countries as the mean age at retirement has risen by a year or two.

\section{The interaction of private and public transfers}

How would we expect the private behavior of individuals to respond to a social system which attempts to change their pattern of consumption over the life cycle by taxing them during their working years and transferring resources to them in childhood and old age? Here, evolutionary theory and economic theory lead to the same expectation: public transfers to the elderly will be offset, at least partially, by countervailing changes in private transfers. This is a prediction of evolutionary theory as sketched earlier, with its balancing of marginal fitness gains from own consumption and transfers to descendants. It is also a prediction of economic theory under Ricardian Equivalence as elaborated by Barro (1974), on the assumption that individuals care about their own wellbeing but also care about the wellbeing of their descendants. Adults decide how much to consume themselves and how much to help their children and their own parents, striking a balance between their own wellbeing and that of their children, grandchildren and more distant progeny. If the government then taxes the adult children to give the elderly more resources through pensions and health care, this theory predicts that the elders will make private transfers to restore the consumption balance across the generations, rather than consume the government transfer themselves.

This theory applies best to people with sufficient income to leave planned bequests to their children and to invest in their children's human capital. They can make adjustments at the margin in the response to changes in public programs. But for those with 
lower and less secure incomes, things might play out differently. We do find some support in NTA for these ideas. Brazil is the country with the most generous public pension system (as we shall see below), and it is also the country with the largest private net transfers from the elderly to their younger family members (Turra, Queiroz, \& Rios-Neto, 2011). The system of familial support of the elderly in Japan appears to have been largely neutralized by the public pension and long-term care programs (Ogawa, Matsukura, \& Chawla, 2011). The public pension system introduced in South Africa greatly increased the incomes of many older rural people, and a number of studies have documented the use of these pension funds by grandmothers to benefit grandchildren through schooling, health care, and improved nutrition. Again, public transfers to the elderly are offset at least in part by private transfers from the elderly to children or grandchildren.

There are also indications of substitution between public and private transfers to children. In Europe, public education is strong and private expenditures on education are very low, as seen in NTA data. However, in Latin America and East Asia, public spending on education is relatively low, and there we see substantial private spending on education.

\section{Funding the gap between consumption and labor income}

The gap between consumption and labor income at a given age can be funded either through use of asset income (that is, by borrowing or by using the part of asset income that is not saved) or by net transfers, that is transfers received minus transfers made to others. Transfers may be public or private. Countries vary greatly in the extent to which the elderly rely on asset income, or public transfers, or familial transfers, to fund their net consumption in old age.

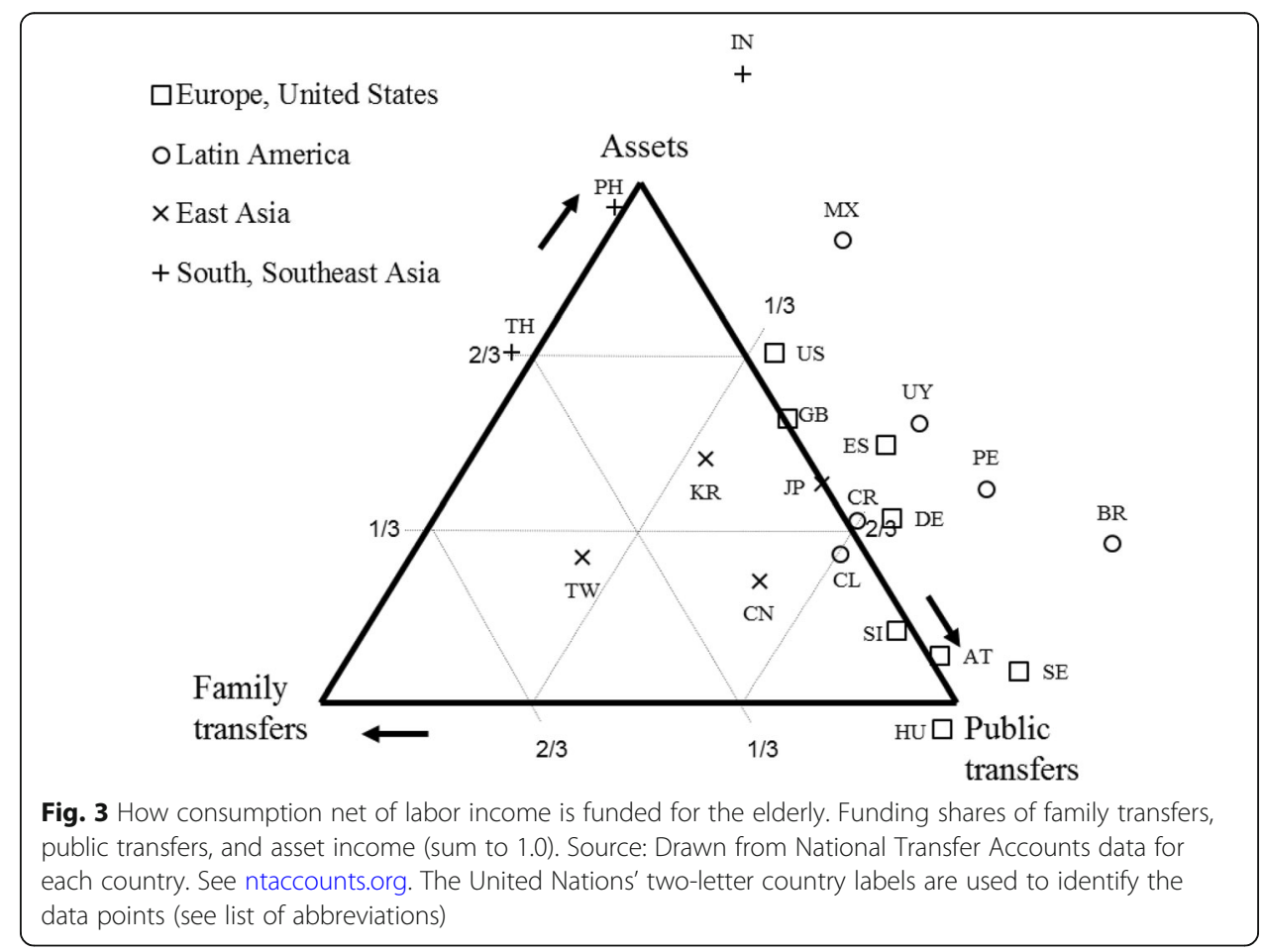


This diversity is depicted in Fig. 3 by plotting the share of old age net consumption (in excess of labor income) funded from each source on a triangle graph. Each point represents a different country, identified using the United Nations' two-letter code. In a country located at the Asset vertex, the elderly are funded $100 \%$ out of asset income and not at all from public or private transfers, as in the Philippines (PH). In countries located at the Public Transfers vertex, the elderly are completely funded by public transfers with no support coming from assets or familial transfers, as in Hungary, Austria, Slovenia, or Sweden. Countries located on the line joining two vertices are funded by a mix of the two respective sources, as in the case of Great Britain (GB), where the elderly are funded half by public transfers and half by assets, or Thailand, where the elderly are funded two thirds by assets and one third by family transfers. In a country towards the middle of the triangle, like Taiwan, China, or S. Korea, net consumption by the elderly is funded roughly equally from all three sources ${ }^{3}$.

There are many countries near the Public Transfers vertex: Austria, Hungary, Slovenia, Sweden, and Brazil, with Germany, Costa Rica, Chile, and Peru funded at least two thirds by public transfers. There are no countries near the Family Transfers vertex, but in Thailand and the three East Asian countries within the triangle the elderly get substantial familial funding. Many countries lie outside the triangle to the right, and in these, the elderly themselves make net transfers to younger family members rather than the reverse. Finally, there are a number of countries where the elderly derive at least two thirds of their support from assets: the USA, Thailand, Philippines, Mexico, and India.

For this diagram, all people 65 and over were grouped together, which conceals an important pattern: younger old people, say 65-75, tend to make net transfers to their children, and older old people, say above 75 , tend to receive net transfers from their children, and in Fig. 3, these counter flows tend to cancel. But as populations age, the share of older old will rise, and so net transfers to the elderly may rise as well. Also, in those countries where the elderly make net transfers to their children and grandchildren, population aging will raise the size of those flows or allow older people to cover the costs of their children (e.g., tuition) with smaller transfers per elder.

\section{Another perspective: the direction of intergenerational flows}

In countries at earlier stages of the demographic transition, there are many children and few elderly, and in some of these countries, the elderly continue to work into old age and consume amounts similar to other adults. In these circumstances, income will be reallocated from the older ages at which much of it is earned to the younger ages at which much of it is consumed. This can be seen by calculating the average age at which output is consumed and the average age at which it is earned in a population. The result will be influenced both by the population age distribution and by features of the age profiles of consumption and labor income. If the average age of consumption is $A_{\mathrm{c}}$ and that of earning is $A_{\mathrm{yl}}$, then the average unit of output flows from $A_{\mathrm{yl}}$ to $A_{c}$. If $A_{c}$ is less than $A_{\mathrm{yl}}$, then income flows downward from older to younger on average; otherwise, income flows upward from younger to older. From the earlier discussion, this flow

${ }^{3}$ In NTA data for more recent years, the importance of familial support for the elderly is much reduced in these three countries (Mason \& Lee, 2018). 
and its direction are the net result of first, the use of saving, asset accumulation, and dissaving to move income from younger to older ages, and second, private and public transfers that reallocate income both upward and downward.

We can plot the average ages for each country using arrow diagrams. Age is on the horizontal axis, and the tail of the arrow is placed at $A_{\mathrm{yl}}$ while the head is at $A_{\mathrm{c}}$. The thickness or width of the arrow is per capita consumption, $c$, and for visual comparison, this is divided by per capita labor income, yl. The area of the arrow, $c\left(A_{c-} A_{\mathrm{yl}}\right)$, is called "life cycle wealth" which can be positive or negative. For present purposes, life cycle wealth is not important; the interested reader will find a discussion in Lee (1994) or Lee and Mason (2011b).

Results for 40 NTA countries as well as two hunter-gatherer groups are shown in Fig. 4 . They are grouped by world region and ranked by per capita income within regions, and the regions are ranked by per capita income as well. Shaded arrows give the averages for each region. We see that hunter-gatherer groups reallocate income strongly downward by 10 or 12 years, from older to younger, as we already knew must be the case based on the age profiles shown in Fig. 1. We see that the same is true for all the countries in Africa, South and West Asia, and Latin America, although the

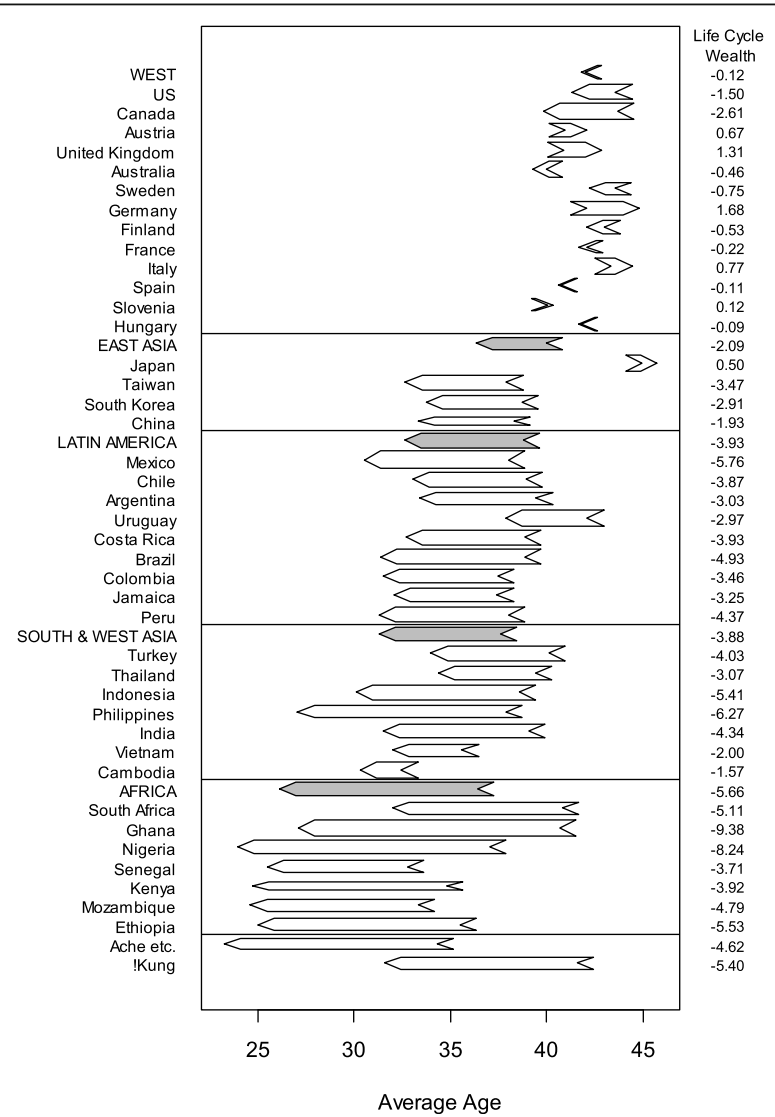

Fig. 4 The direction of income reallocation over the life cycle. Note: Head of arrows is average age of consumption, and tail is average age of production. Countries ranked within region by per capita GDP (ppp-adjusted, US\$) in 2005. Regional averages are unweighted. Regions ranked by per capita GDP. Source: For Ache etc. and !Kung, see note to Fig. 1. For National Transfer Accounts data, see ntaccounts.org. Average age and per capita calculations use United Nations Population Division (2013) population data for year of NTA age profile 
arrows are much shorter in some countries such as Cambodia, Vietnam, or Uruguay. In East Asia, despite very low fertility and substantial familial support of the elderly, China, Taiwan, and S. Korea all have strongly downward transfers. For Japan, however, with a much older population and with generous public transfers to the elderly and high old age consumption, the arrow points upwards. In the "West" region, Slovenia, Italy, Germany, Austria, and the UK all have upward pointing arrows, and the average for the region is only very slightly downward. A small amount of population aging would reverse the arrows for several additional countries and the region as a whole. These reversals of direction are the vanguard of a deep and dramatic shift from societies in which all adults generated a surplus which flowed downward for investments in children, to elder-oriented societies with a high proportion of older people who consume a great deal and work very little (Lee, 2000; Lee \& Mason, 2011a). The inclusion of time transfers in this analysis would raise downward transfers to children while leaving upward transfers to the elderly largely unchanged, since the elderly for the most part care for one another (Gál and Vanhhuysse, 2018).

\section{The direction of private transfers}

Figure 4 portrays the reversal of a pattern that had probably lasted as long as humanity. The reversal is due in part to the aging of the populations which is itself a watershed event, and in part to the changes in the economic life cycle that we discussed earlier, including the rising importance of physical and financial assets. Here our focus is on intergenerational transfers, and we will begin with private or familial transfers which are the most fundamental and were the only kind of transfers for tens of thousands of years.

Private transfers are the sum of interhousehold transfers as reported on surveys and intrahousehold transfers calculated based on the income and consumption of household members. As we have seen, in some countries, the elderly receive substantial net private transfers, but more typically the elderly on net make transfers to younger family members. There are also important variations in transfers to children. These occur in part because in rich countries public education is strong and private spending on education is very low (except in the rich countries of East Asia), while in Latin America, Asia, and Africa, public education is relatively less strong so private spending on education is relatively higher. Variations also derive from differences in fertility which is hyper-low in some countries and high in others.

The direction and magnitude of private transfers can be portrayed using the same design as for the reallocations of Fig. 4. The tail of the arrow is placed at the average age of private transfers made, and the head at private transfers received. The private transfers for hunter-gatherers are identical to the reallocations shown in Fig. 4, because they had neither physical property nor government. The NTA countries are shown in Fig. 5, which tells a simple story: private transfers are strongly downward from older to younger in every country. (Colombia appears to be an outlier with private transfers that are only barely downward. I suspect that this will turn out to be a data issue.) Even in those countries with strong familial support of the elderly, strong transfers to children dominate upward transfers to elderly parents, even with extremely low fertility. In these countries, the arrows, although perhaps somewhat shorter than for other countries, still 


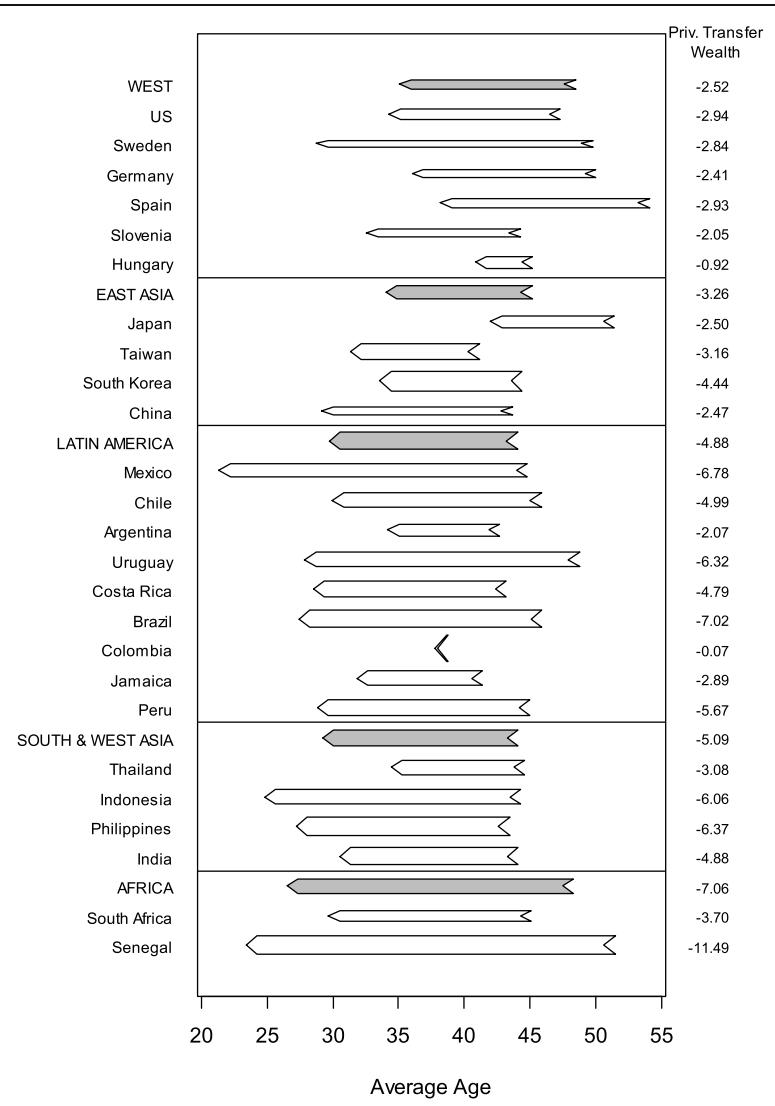

Fig. 5 The direction and magnitude of private transfer flows. Note: Head of arrows is average age of receiving transfer, and tail is average age of giving transfer. Countries ranked within region by per capita GDP (ppp-adjusted, US\$) in 2005. Regional averages are unweighted. Regions ranked by per capita GDP. Source: National Transfer Accounts data. For data, see ntaccounts.org. Average age and per capita calculations use United Nations Population Division (2013) population data for year of NTA age profile

point strongly downward. The thinner arrows for the West reflect the low private spending on education in that region.

The net private transfer per child is the difference between the total transfer from parents to the child and later transfers from the same child as an adult to the now elderly parents. The parental expectations of this net transfer are the "price" they face for raising the child. The fact that net private transfers are so strongly downward in every one of these 40 countries (except, perhaps, Colombia) at all levels of development suggests that a simple interpretation of Caldwell's (1976) wealth flows theory of the fertility transition is not consistent with these facts. I say a "simple version" because only the money value of transfer flows is measured here, and it is possible that children's contributions through insurance value, physical security, and political power might tip the balance.

\section{The direction of public transfers}

At earlier stages of development, public transfers are primarily for education and health care. At a later stage, public pensions are introduced, usually initially for the military and for civil servants later extending to the formal sector and then to the whole labor force. At earlier stages of development, public expenditures on health care are higher 
for children, and then as development proceeds, they become more flat across age and then distinctly favor the elderly as in the rich countries today (Mason \& Miller, 2018). Another portion of public transfers is not age-targeted but rather is for social infrastructure, military, police, and other public goods. NTA allocates these public expenditures equally across individuals of all ages.

Using the same design, Fig. 6 portrays the direction and extent of public transfers. The thickness of the arrows represents the volume of public transfers relative to labor income. In Africa and in South and West Asia, the arrows are thin reflecting a small role of public spending, and all point strongly downward. Many Latin American countries adopted European style pension programs at an early stage while keeping a relatively low level of spending on public education, which accounts for the short but fatter arrows in this region, with some pointing upwards: Brazil, Uruguay, and Argentina (barely). In East Asia, public sector transfer programs are relatively small outside of Japan, despite the high incomes of Taiwan and S. Korea. Japan has generous public pensions and publicly funded health care and long-term care, and a fat upward pointing arrow to show for it. All the countries in the West have upward pointing arrows except for the USA (which has a relatively young population, a small public pension benefit, and a strong reliance on asset income).

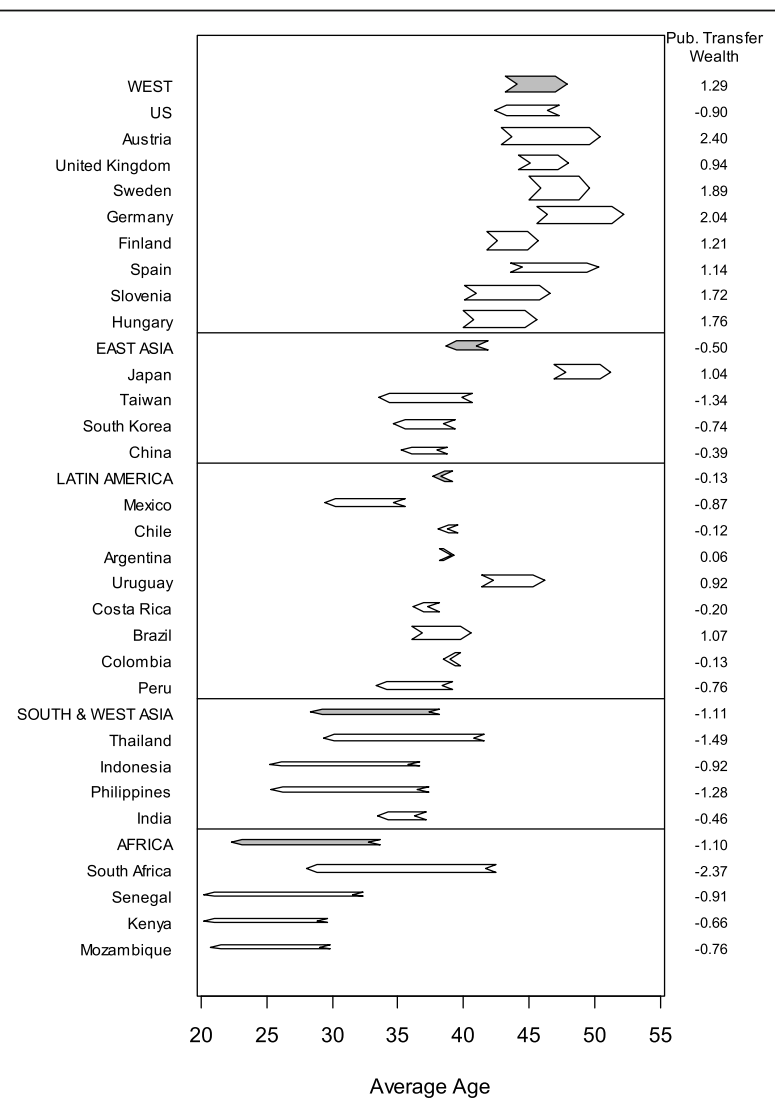

Fig. 6 The direction of flow for public transfers. Note: Head of arrows is average age of receiving benefit, and tail is average age of paying tax. Countries ranked within region by per capita GDP (ppp-adjusted, US\$) in 2005. Regional averages are unweighted. Regions ranked by per capita GDP. Source: For National Transfer Accounts data, see ntaccounts.org. Average age and per capita calculations use United Nations Population Division (2013) population data for year of NTA age profile 
Public transfers alter the net costs and private incentives for behavior such as childbearing, schooling, saving, retirement, and entering a nursing home. Beyond these incentives, public transfers also create externalities or spillover effects for behavior, and this is particularly true for fertility (Wolf, Lee, Miller, Donehower, \& Genest, 2011).

It is also instructive to consider total transfers, the sum of public and private, because as noted earlier these appear to substitute for one another across countries, at least to some degree. We can see the direction and volume of the total transfers in Fig. 7 which plots their arrows. Recall that private transfers were uniformly downwards in all countries, while public transfers were downward in Africa and South/Southeast Asia, mixed in Latin America and East Asia, and upward in Western nations (except for the US). Total transfers are downward by a lot in the lower income regions and by a slight amount in the West (except for Hungary), but as the Western and East Asian populations age the direction of these arrows will in many cases flip upward in coming decades.

\section{Effect of rising longevity}

Population aging happens in two ways-through low fertility which reduces the number of workers relative to the number of elderly, and through low mortality which means

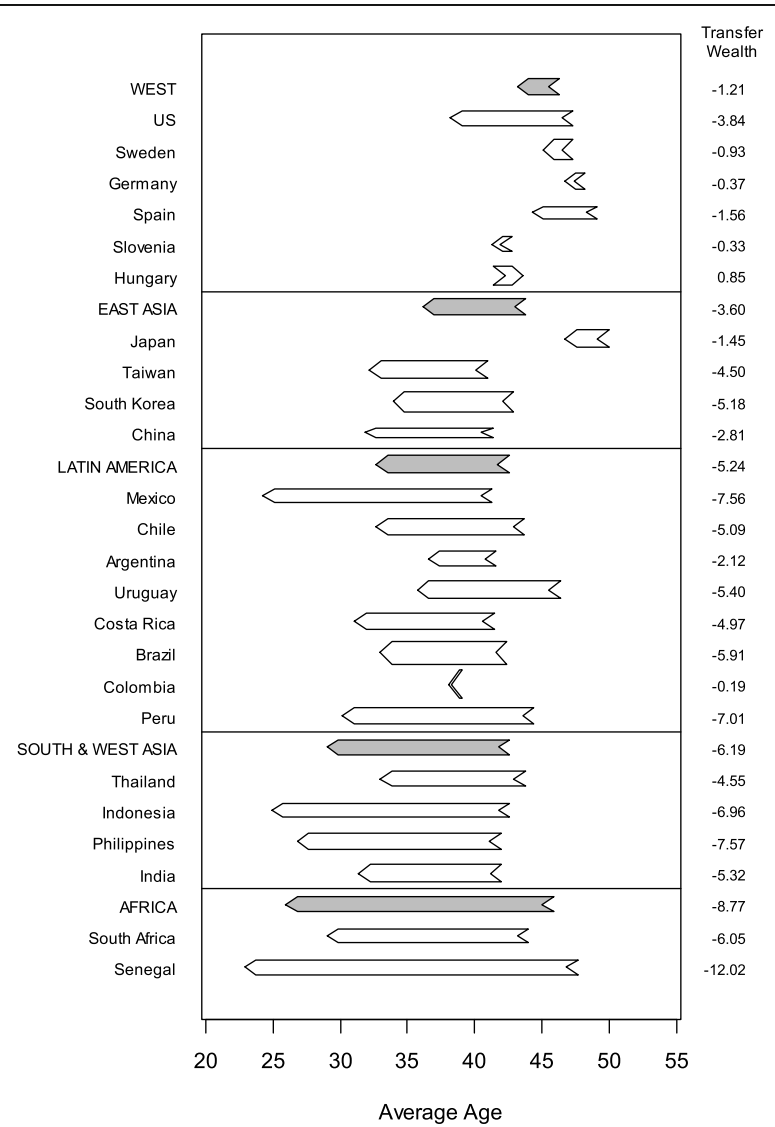

Fig. 7 Direction of total transfer flows (public + private). Note: Head of arrows is average age of receiving public plus private transfers, and tail is average age of paying tax or making private transfer. Countries ranked within region by per capita GDP (ppp-adjusted, US\$) in 2005. Regional averages are unweighted. Regions ranked by per capita GDP. Source: For National Transfer Accounts data, see ntaccounts.org. Average age and per capita calculations use United Nations Population Division (2013) population data for year of NTA age profile 
that the average person spends more years in old age. The economic consequences of the two sources of aging are different, and here I will discuss the consequences of rising longevity from an analytic perspective, drawing on the age profiles of consumption and labor earning (Fig. 8).

As noted in Lee (1994) and Eggleston and Fuchs (2012), as mortality declines, even though individual lives are always lengthened at the end, for the population as a whole, the person-years gained do not occur at the end of life, but rather occur throughout the life cycle. When mortality is high with life expectancies at birth $\left(e_{0}\right)$ in the 20 s or 30 s, the person-years of life gained are mainly in childhood. As mortality decline proceeds, subsequent gains occur mainly in the working ages. Finally, they come to occur mostly in old age, which is the situation in recent decades and will be even more so in the future (Lee, 1994).

It is instructive to plot the age distribution of gains in person years lived against the economic life cycle to assess their interaction, as in Fig. 8. Multiplying together the difference between consumption and labor income on the one hand and the distribution of person years gained (when $\mathrm{e}_{0}$ rises by one year), and summing, gives the proportionate increase in the cost of net lifetime consumption. This can be expressed as a proportion of the present value of lifetime consumption. In the USA, each additional year of $\mathrm{e}_{0}$ costs $1.4 \%$ of lifetime consumption. To accommodate the consumption cost of living one additional year, we must reduce consumption at every age by $1.4 \%$ or we must work $1.4 \%$ more at every age, or we must retire enough later to generate $1.4 \%$ more labor income.

With an average initial working life of 40 years, this would mean postponing retirement by a half year for each 1 -year increase in $\mathrm{e}_{0}(.56=.014 \times 40)$. All these

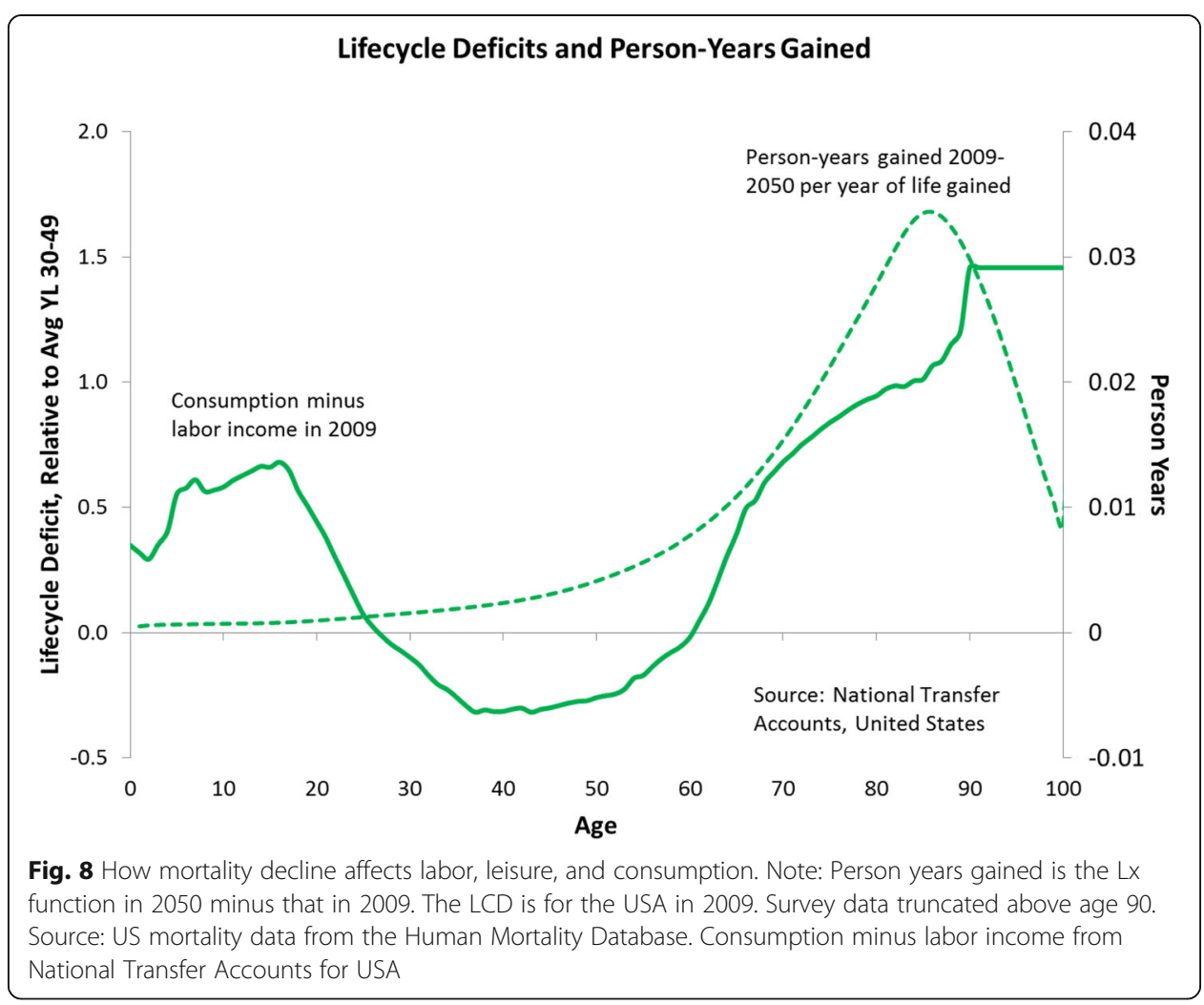


calculations are done without any discounting, but since a reduction in consumption or increase in earnings earlier in the life cycle would lead to increased savings which could then be invested to pay for a longer retirement, discounting is appropriate. At a $3 \%$ real discount rate, the "cost" of longer life falls to .4\% of consumption per year going forward, so all the adjustments above would be reduced by two thirds or three fourths, and longer life appears to be much less costly. Adjustments made earlier in the life cycle are more effective than those made later like postponed retirement.

\section{Population aging and public transfers}

We can get a different perspective on the economic consequences of population aging by using population projections together with baseline age profiles of public and private intergenerational transfers. Intergenerational transfers are particularly important, because they determine the extent to which the elderly are dependent. We naturally view the elderly as dependent because they consume much more than the little they earn. But output is produced from inputs of both labor and capital. Younger adults supply a lot of labor (and human capital) but not much physical or financial capital. Older adults supply a lot of physical and financial capital but not much labor. The assets of the elderly generate income just as the labor of younger adults does, and we should not disregard it. Arguably, the elderly are dependent only to the extent that they depend on transfers from working age adults for their consumption, transfers that may be public or private. This is why it is so important to consider intergenerational transfers when we think about the economic impact of population aging.

We will begin by considering public transfers. It is well known that public transfers in many countries are fiscally unsustainable as currently structured, in the face of projected population aging. It is less well known that in some other countries population aging may actually be fiscally beneficial, which occurs if the elderly pay more in taxes than they receive in benefits and if transfers are largely to children.

All countries have some level of public education, which means that all can benefit fiscally from lower fertility and declining proportions of children in the population. In low- and middle-income countries, this is typically the main public transfer program. However, all rich countries and many lower- and middle-income countries also have public pension programs and public provision of health care. Depending on the balance of these programs, and on the extent of elder tax payments, population aging may bring fiscal relief or, more often, impose fiscal hardship, based on current program structures. It seems very likely, however, that as incomes rise the public programs of the less wealthy countries will come to resemble more closely those of the rich nations, making the "current program structure" assumption less relevant and making population aging more costly. Nonetheless, I will focus here on the interactions of current program structures with population aging. These should not be interpreted as projections but rather as analytic calculations of the purely demographic component of future changes.

The specific calculation multiplies the projected population age distributions times the current age profiles of benefits minus taxes by age and sums to get the total net cost or surplus for each future year up to 2050. The public transfer load is this sum divided by the total consumption projected for that year based on the initial consumption 


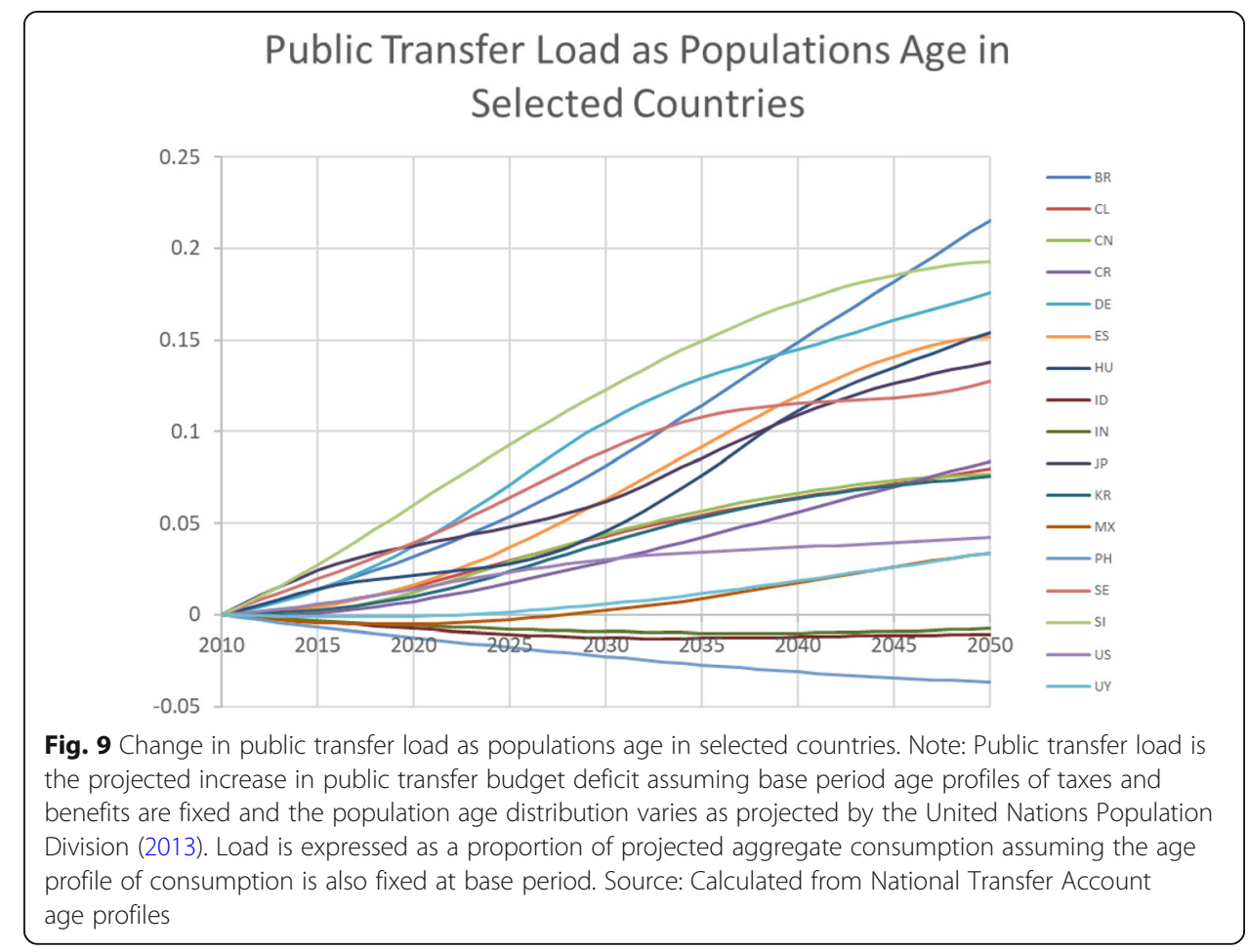

age profiles. To focus on the projected changes, this public transfer load is standardized to 0 in 2010.

The results are shown in Fig. 9. We see that almost all countries are projected to have an increasing public transfer load as populations age. Those with declining loadsIndia, Indonesia, and the Philippines-have these in part due to their profiles of public transfers but also because they are still early in the demographic transition and will not begin aging for two or three decades. The rest of the countries, even those with relatively small programs for the elderly, show a rising load of public transfers as the population ages. Slovenia, Brazil, and Germany show the greatest increases, followed by Spain, Hungary, Japan, and Sweden. The first group has increases of about $20 \%$ in the ratio. If there were no change in these benefits or in government borrowing, then achieving balance would require an offsetting $20 \%$ increase in tax revenues. It is far more plausible that governments will enact reforms in the public programs incorporating some combination of benefit cuts and tax increases.

\section{Population aging and private transfers}

Public intergenerational transfers are only a part of the story. Private or familial intergenerational transfers are also pervasive, and with NTA data, we can examine the effect of population aging on these as well.

In the triangle diagram of Fig. 3, we saw that the elderly of most nations either make net transfers to younger people or have a net transfer flow close to zero. In only a few East Asian countries and Thailand do families make appreciable net transfers to the elderly. As populations age, there is a private transfer benefit in most countries with more elderly to assist their younger family members. This appears as an increasingly negative transfer cost in Fig. 10 which plots the private transfer load as projected from 


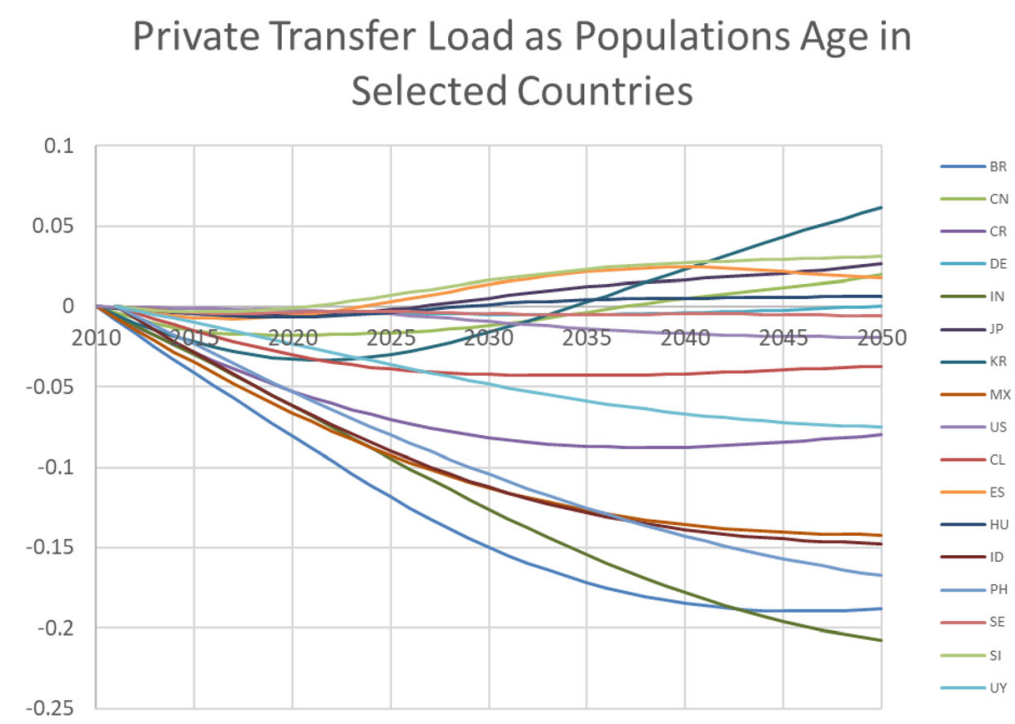

Fig. 10 Change in private transfer load as populations age in selected countries. Note: Private transfer load is the projected increase in private transfers received minus transfers given assuming base period age profiles of these are fixed and the population age distribution varies as projected by the United Nations Population Division (2013). Load is expressed as a proportion of projected aggregate consumption assuming the age profile of consumption is also fixed at base period. Source: Calculated from National Transfer Account age profiles

2010 to 2050 after being set to 0 in 2010 so that changes can be seen more clearly. Leading examples of countries with these declining loads are Brazil, Mexico, India, Philippines, and Costa Rica. In the USA, the load declines somewhat. In the Asian countries with strong family support of the elderly, the opposite occurs: population aging raises the support cost substantially. Leading examples here are S. Korea and China. In S. Korea, which is already aging, the load initially declines as child dependency drops and then rises very strongly. Surprisingly, however, Japan also has a strongly rising cost. The reason is that Japan, like a number of other countries that are near the zero line in the triangle figure, has strong downward transfers from the elderly from ages 65 to 78, but after that has strong upward transfers from children to provide support for their elderly parents. These opposing flows cancel and are hidden in the triangle figure, but as population ages, the balance shifts toward the oldest old who are net receivers of care, and the net support costs rise. That is what we see happening for Japan in Fig. 10, and also for Slovenia, Spain, and some other European countries.

\section{Population aging and the total transfer load}

Countries vary greatly in the extent to which the young and the old rely on public and private transfers, so to get a complete picture, we need to consider both. Adding together the public and the private transfers at each age, we can calculate the total transfer load, set it to zero in 2010 for each country, and observe the changes as shown in Fig. 11.

The most striking change in Fig. 11 is for Brazil. Brazil had the heaviest public transfer load by 2050, but when we take into account the strong net private transfers Brazilian elders make, the total transfer load initially declines and then rises modestly, ending up not much above zero. A number of developing countries would see declining total 


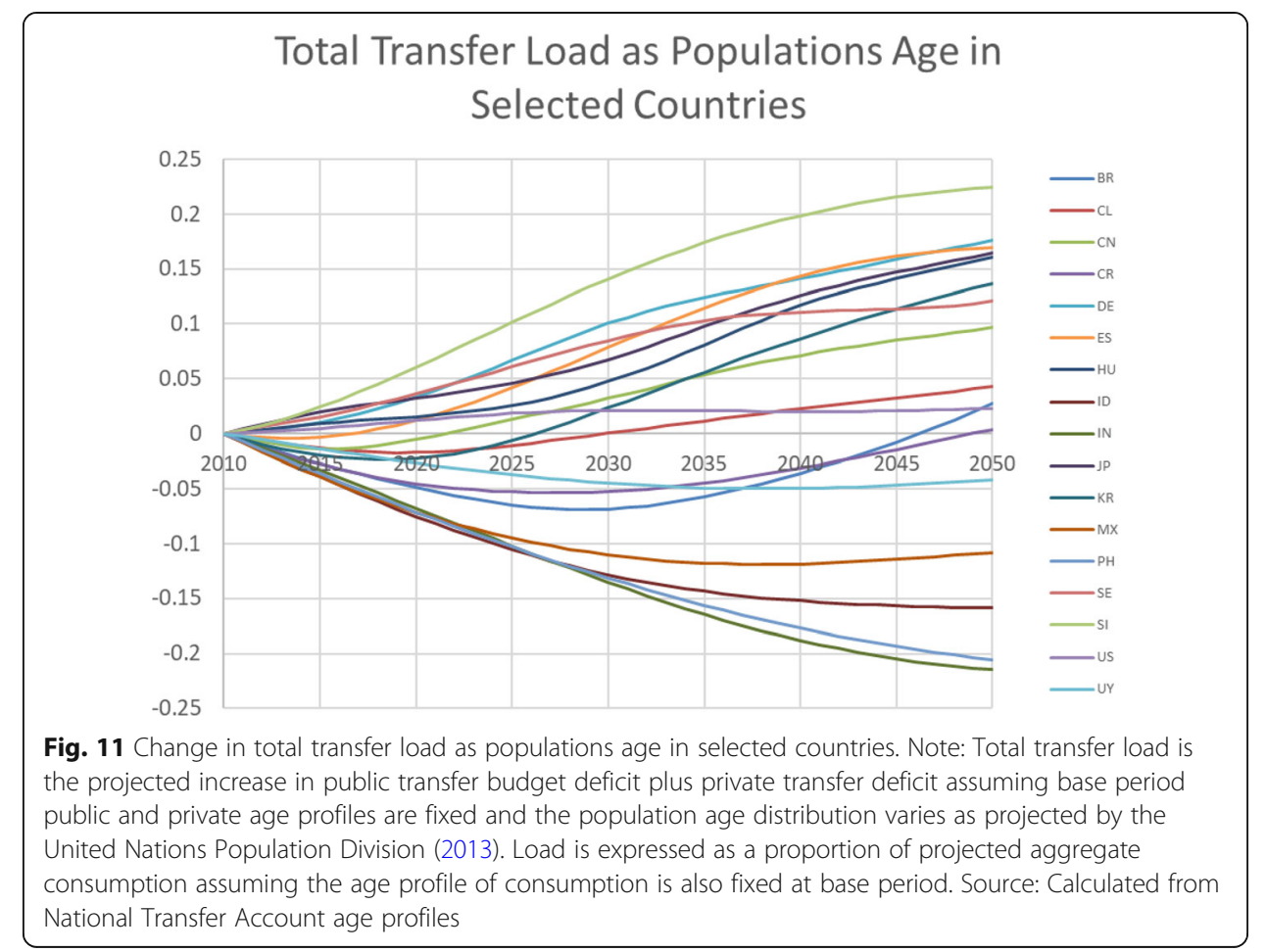

transfer loads under current public program structures, such as India, Indonesia, Philippines, and Mexico. In the countries with generous public transfers to the elderly, private transfers by the elderly are not enough to change the challenging outlook, particularly for Slovenia, Germany, Sweden, Spain, and Japan. In the USA, the transfer load rises only very modestly.

\section{Conclusions}

From our evolutionary pasts as hunter-gatherers, we have inherited core features: a long period of child dependency, extensive intergenerational transfers to children, cooperative breeding, and social sharing of food including with non-kin. Older people in that context continued to produce a surplus over their consumption, and to transfer it to the young. These practices may have persisted during low-density agriculture, but in higher density agriculture where land and residences were valuable and likely to be owned by older people, labor supply at older ages was sharply reduced and older people became net consumers relative to their labor income, although in some countries they have remained net producers if we take their asset income into account. In some Asian societies today, the elderly live with their adult children and receive net transfers from them, but in most societies, the elderly continue to make net transfers to their children out of asset income or out of public pensions. With the growth of governmental intergenerational transfers, private transfers have been reduced or, at times, have reversed their direction so as to offset the government programs. Among the rich nations, a number have experienced a reversal of intergenerational flows from downward, as in our evolutionary and agricultural past, to upwards, from young to old. Nonetheless, private transfers remain strongly downward, from older to younger, everywhere in the world. With these extensive net public transfers, the population aging that is projected 
for coming decades will lead to fiscal instability unless there are major program reforms. However, in many countries, the elderly make net private transfers to their children and grandchildren. In this case, population aging will permit children to receive the same net private transfers per child for which each elder contributes less, or permit children to receive increased transfers per child for which each elder contributes the same as before. In these ways, population aging can make private transfers less costly, partially offsetting the increased costs through public transfers.

\section{Abbreviations}

NTA: National Transfer Accounts; GDP: Gross Domestic Product; RME: Resting metabolic energy; $e_{0}$ : Life expectancy at birth; ppp: Purchasing power parity; US: United States; GB: Great Britain; PH: Philippines; BR: Brazil; CN: China; CR: Costa Rica; IN: India; DE: Germany; JP: Japan; KR: S. Korea; MX: Mexico; CL: Chile; ES: Spain; HU: Hungary; ID: Indonesia; SE: Sweden; SI: Slovenia; UY: Uruguay; TH: Thailand; TW: Taiwan; AT: Austria; PE: Peru

\section{Acknowledgements}

I am grateful to members of National Transfer Accounts (NTA) country teams for use of their data and to Gretchen Donehower for assistance. The NTA researchers are identified, and more detailed information is available on the NTA website: www.ntaccounts.org.

\section{Author's contributions}

There is only one author, who contributed the entire submission. The author read and approved the final manuscript.

\section{Author's information}

Ronald Demos Lee, rlee@demog.berkeley.edu, Professor in the Graduate School, Demography and Economics, University of California Berkeley.

\section{Funding}

Research for this paper was funded by a grant from the National Institutes on Aging, NIA R37 AG025247.

\section{Availability of data and materials}

The data used in this paper are presented in charts. The author will make available the data plotted in the charts on request.

\section{Competing interests}

The author declares that he has no competing interests.

Received: 24 July 2020 Accepted: 27 August 2020

Published online: 21 September 2020

\section{References}

Barro, R. J. (1974). Are government bonds net wealth? Journal of Political Economy, 28(6), 1095-1117.

Becker, Gary S. and Kevin M. Murphy (1988) "The Family and the State," Journal of Law and Economics (April) v.31 n.1, pp. 118.

Boserup, E. (1965). The conditions of agricultural growth: The economics of agrarian change under population pressure. Chicago: Aldine Publishing Co.

Boserup, Ester (1981) Population and technological change (University of Chicago Press)

Burkart, J. M., O. Allon, F. Amici, C. Fichtel, C. Finkenwirth, A. Heschl, J. Huber, K. Isler, Z. K. Kosonen, E. Martins, E.J. Meulman, R. Richiger, K. Rueth, B. Spillmann, S. Wiesendanger, \& \& C. P. van Schaik (2014) “The evolutionary origin of human hypercooperation" Nature (Aug 27).

Caldwell, John C. (1976) "Toward a restatement of demographic transition theory," Population and Development Review, reprinted as Chapter 4 of John Caldwell (1982) Theory of Fertility Decline (Academic Press), pp. 113-180.

Chu, C.Y. and Ronald Lee (2006) "The co-evolution of intergenerational transfers and longevity: An optimal life history approach." Theoretical Population Biology (March) V.69 n.2., pp. 193-201.

Chu, C. Y.C., and Lee, R.D. 2012. "Sexual dimorphism and sexual selection: A unified economic analysis," Theor. Popul. Biol. https://doi.org/10.1016/j.tpb.2012.06.002

Chu, C. Y., \& Lee, R. D. (2013). On the evolution of intergenerational division of labor, menopause and transfers among adults and offspring. Journal of Theoretical Biology, 332, 171-180 http://authors.elsevier.com/sd/article/\$0022519313001999.

Domar, Evsey (1970) "The causes of slavery or serfdom: A hypothesis" Journal of Economic History, 30, pp 18-32. doi:10.1017/ S0022050700078566. Read only Part I, pp.18-23. http://www.jstor.org/stable/2116721

Eggleston, K. N., \& Fuchs, V. R. (2012). The new demographic transition: Most gains in life expectancy now realized late in life. Journal of Economic Perspectives, 26(3), 137-156.

Gál, R. I., Vanhuysse, P., \& Vargha, L. (2018). Pro-elderly welfare states within child-oriented societies. Journal of European Public Policy, 25(6), 944-958. https://doi.org/10.1080/13501763.2017.1401112.

Gollin, D. (2002). Getting income shares right. Journal of Political Economy, 110(2), 458-474.

Gurven, M. (2004). To give and to give not: The behavioral ecology of human food transfers. Behavioral and Brain Sciences, 27, 543-583.

Hill, K. and A.M. Hurtado. 2009. Cooperative breeding in South American hunter-gatherers. Proc. R. Soc. B published online 19 August 2009. doi: https://doi.org/10.1098/rspb.2009.1061. 
Howell, N. (2010). Life histories of the Dobe !Kung. Berkeley: University of California Press.

Hrdy, S. (2009). Mothers and others: The evolutionary origins of mutual understanding. Cambridge, MA: Harvard University Press.

Kaplan, H. (1994). Evolutionary and wealth flows theories of fertility: Empirical tests and new models. Population and Development Review, 20(4), 753-791.

Kaplan, H., \& Gurven, M. (2005). The natural history of human food sharing and cooperation: A review and a new multiindividual approach to the negotiation of norms. In H. Gintis, S. Bowles, R. Boyd, \& E. Fehr (Eds.), Moral Sentiments and Material Interests: The Foundations of Cooperation in Economic Life, (pp. 75-114). England: MIT Press, Cambridge MA and London.

Kramer, K. (2005). Maya children: Helpers at the farm. Cambridge: Harvard University Press.

Kuzawa, Christopher W., Harry T. Chugani, Lawrence I. Grossman, Leonard Lipovich, Otto Muzik, Patrick R. Hof, Derek E. Wildman, Chet C. Sherwood, William R. Leonard, and Nicholas Lange (2014) "Metabolic costs and evolutionary implications of human brain development" PNAS http://www.pnas.org/cgi/doi/10.1073/pnas.1323099111 (PNAS early edition).

Lee, R. (1994). The formal demography of population aging, transfers, and the economic life cycle. In L. Martin, \& S. Preston (Eds.), The Demography of Aging, (pp. 8-49). Washington, DC: National Academy Press.

Lee, R. (2000). A cross-cultural perspective on intergenerational transfers and the economic life cycle. In A. Mason, \& G. Tapinos (Eds.), Sharing the wealth: Demographic change and economic transfers between generations, (pp. 17-56). Oxford: Oxford University Press.

Lee, R. (2014). Intergenerational transfers, social arrangements, life histories, and the elderly. In M. Weinstein, \& M. A. Lane (Eds.), Sociality, Hierarchy, Health: Comparative Biodemography: Papers from a Workshop. Washington, D.C.: National Academies Press.

Lee, Ronald and Gretchen Donehower (2011) "Private transfers in comparative perspective" Chapter 8 in R. Lee and A. Mason (eds.), Population aging and the generational economy: A global perspective. Edward Elgar. (viewable on the IDRC website http://www.idrc.ca/EN/Resources/Publications/Pages/IDRCBookDetails.aspx?PublicationID=987)

Lee, Ronald, Gretchen Donehower, and Tim Miller (2011) "The changing shape of the economic lifecycle in the United States, 1960 to 2003" Chapter 15 in R. Lee and A. Mason (eds.), Population aging and the generational economy: A global perspective. Edward Elgar. (viewable on the IDRC website http://www.idrc.ca/EN/Resources/Publications/Pages/ IDRCBookDetails.aspx?Publication|D=987).

Lee, Ronald and Karen Kramer (2002) "Children's economic roles in the context of the Maya family life cycle: Cain, Caldwell, and Chayanov Revisited," Population and Development Review, 28 (3):475-499 (September 2002).

Lee, Ronald and Andrew Mason. (2011a) "Generational economics in a changing world" in Ronald Lee and David Reher (eds), Demographic transition and its consequences, special supplement to population and development review. 37:115-142. PMCID: PMC3143474; PMID: 21804657 http:/www.ncbi.nlm.nih.gov/pmc/articles/PMC3143474/

Lee, R. and A. Mason, principal authors and editors (2011b). Population aging and the generational economy: A global perspective. Cheltenham, UK, Edward Elgar.

Lee, Ronald, Hillard Kaplan and Karen Kramer (2002) "Children and elderly in the economic life cycle of the household: A comparative study of three groups of foragers and horticulturalists." Paper presented at the Annual Meetings of the Population Association of America.

Mason, Andrew and Ronald Lee (2018) "Intergenerational transfers and the older population", National Academies of Sciences, Engineering, and Medicine in Future Directions for the Demography of Aging: Proceedings of a Workshop. Washington, DC: The National Academies Press. doi: https://doi.org/10.17226/25064.

Mason, Carl N. \& Miller, Timothy, 2018. "International projections of age specific healthcare consumption: 2015-2060," The Journal of the Economics of Ageing, Elsevier, vol. 12(C), pages 202-217.

Mueller, E. (1976). The economic value of children in peasant agriculture. In R. Ridker (Ed.), Population and development: The search for interventions, (pp. 98-153). Baltimore: Johns Hopkins Press.

Ogawa, Naohiro, Rikiya Matsukura, and Amonthep Chawla (2011) "The elderly as latent assets in aging Japan" in R. Lee and A. Mason (eds.), Population aging and the generational economy: A global perspective. Edward Elgar. (viewable on the IDRC website http://www.idrc.ca/EN/Resources/Publications/Pages/IDRCBookDetails.aspx?PublicationID=987.

Population Division (2013). National Transfer Accounts manual: Measuring and analyzing the generational economy. New York: United Nations

Sear, R., \& Mace, R. (2008). Who keeps children alive? A review of the effects of kin on child survival. Evolution and Human Behavior, 29, 1-18.

Stecklov, G. (1997). Intergenerational resource flows in Cote d'Ivoire: Empirical analysis of aggregate flows. Population and Development Review, 23(3), 525-553.

Turra, Cassio M., Bernardo L. Queiroz, and Eduardo L.G. Rios-Neto (2011) "Idiosyncrasies of intergenerational transfers in Brazil" in R. Lee and A. Mason (eds.), Population aging and the generational economy: A global perspective. Edward Elgar. (viewable on the IDRC website http://www.idrc.ca/EN/Resources/Publications/Pages/IDRCBookDetails.aspx?PublicationID=987

United Nations Population Division (2013) World population prospects: The 2012 revision. New York.

Wolf, D. A., Lee, R. D., Miller, T., Donehower, G., \& Genest, A. (2011). Fiscal externalities of becoming a parent. Population and Development Review (June), 37(2), 241-266.

\section{Publisher's Note}

Springer Nature remains neutral with regard to jurisdictional claims in published maps and institutional affiliations. 